Redhead, J.W.; Hinsley, S.A.; Beckmann, B.C.; Broughton, R.K.; Pywell, R.F.. 2018. Effects of agri-environmental habitat provision on winter and breeding season abundance of farmland birds. Agriculture, Ecosystems and Environment, 251. 114-123. https://doi.org/10.1016/j.agee.2017.09.027

(C) 2017 Elsevier B.V.

This manuscript version is made available under the CC-BY-NC-ND 4.0

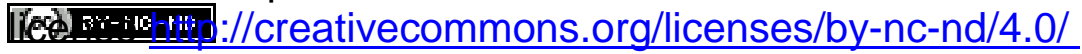

This version available http://nora.nerc.ac.uk/id/eprint/518690/

NERC has developed NORA to enable users to access research outputs wholly or partially funded by NERC. Copyright and other rights for material on this site are retained by the rights owners. Users should read the terms and conditions of use of this material at http://nora.nerc.ac.uk/policies.html\#access

NOTICE: this is the author's version of a work that was accepted for publication in Agriculture, Ecosystems and Environment,. Changes resulting from the publishing process, such as peer review, editing, corrections, structural formatting, and other quality control mechanisms may not be reflected in this document. Changes may have been made to this work since it was submitted for publication. A definitive version was subsequently published in Agriculture, Ecosystems and Environment, 251. 114-123. https://doi.org/10.1016/j.agee.2017.09.027

www.elsevier.com/ 


\section{Effects of agri-environmental habitat provision on winter and breeding season}

2 abundance of farmland birds

3

4

5

6

7

${ }^{1}$ Corresponding author, email: johdhe@ceh.ac.uk

\section{Abstract}

12 Farmland bird populations continue to show declines in spite of over 20 years of research and

13 implementation of agri-environmental schemes (AES) intended to reverse this. Although it is well

14 known that provision of winter food resources can attract farmland birds, there is continuing uncertainty over the ability of AES to provide tangible benefits for target species in terms of increased abundance. Answering these questions is hampered by interannual fluctuations in bird populations and the mobility and territoriality of farmland birds, which have complicated the interpretation of previous studies.

We monitored birds for five years on a large arable estate in central England managed under varying levels of AES uptake (low level uptake of simple and widely applicable AES options, more extensive uptake of more complex AES options), and two control treatments (on-site and off-site). Bird abundance in winter and both total abundance and number of territories in the breeding season were calculated from monthly visits to 16 transects. 
Several species showed significantly higher winter abundance on AES treatments, particularly granivorous species (e.g. reed bunting, yellowhammer, linnet). Many other species (e.g. blackbird, chaffinch, robin) also showed significant differences in winter abundance between treatments on the estate and off-site controls. In the breeding season, linnet, reed bunting, goldfinch and combined granivorous birds showed higher abundance or number of territories on AES treatments compared to on-site controls. For most other species the differences were only significant between treatments on the estate and off-site controls. Independently of AES treatment, a lower coverage of cereals or greater Shannon diversity of crops in the local landscape also had a positive effect on the abundance of many species.

Our results suggest that well-implemented AES can significantly enhance local populations of both farmland specialists of conservation concern and generalist species. Our results also show that, in many cases, these effects were only demonstrable at the farm scale, in comparison with off-site controls. This is probably due to high levels of movement and dispersal of birds resulting in a farmscale spill-over of beneficial effects of agri-environment measures. Our results therefore highlight the importance of thinking beyond the single-farm scale when designing schemes or studies for monitoring the effectiveness of AES, and the importance of selecting appropriately located controls.

Keywords: Agri-environment, farmland birds, population, landscape, arable, supplementary feeding 


\section{Introduction}

42 Agricultural intensification has led to widespread declines in farmland biodiversity over the last century (Donald et al., 2001; Newton, 2004; Kleijn et al., 2011). Changes in farm management, including removal of semi-natural habitats, increased pesticide and fertilizer input and more efficient harvesting have all had deleterious impacts on farmland wildlife, including birds. Farmland birds have undergone severe declines across the EU (Donald et al., 2001; Donald et al., 2006; EBCC, 2016), and particularly in the UK (DEFRA, 2015). Whilst the exact mechanisms of negative impacts of agriculture on populations vary between species, many share the loss of breeding and foraging habitat due to removal of semi-natural features and increased management intensity, and the loss of food resources in terms of invertebrates and seeds (Fuller, 2000). For many granivorous birds, declines have been driven by the loss of overwinter food resources caused by increased herbicide use and the dominance of autumn-sown cereals (Wilson et al., 2009). For insectivorous species, loss of foraging habitat and reduced invertebrate food resources in the breeding season have been identified as important drivers of declines (Potts, 1986; Campbell et al., 1997; Schaub et al., 2010).

One of the key mechanisms for promoting population recovery of farmland birds are agrienvironment schemes (AES). The major AES intervention directly aimed at farmland birds has been the provision of winter food resources by sowing areas of seed-bearing plants as an option for participating farmers. Such resources are well known to be utilised by a wide range of farmland birds, although the quality and quantity of the food provided can vary greatly with plant type and subsequent management (Vickery et al., 2009; Hinsley et al., 2010; Field et al., 2011) and across space and time (Vickery et al., 2009; Davey et al., 2010a). There is also evidence that many sown winter bird-food patches are largely depleted of seed by late winter, leaving birds with insufficient resources (Perkins et al., 2008; Siriwardena et al., 2008; Hinsley et al., 2010). Whilst some agrienvironmental management options have been introduced to address this issue (e.g. extended 
overwinter stubbles, supplementary seed feeding), their efficacy is relatively unexplored (but see Siriwardena et al., 2007).

In addition to overwinter food, AES can also provide habitat for foraging and nesting in the breeding season via creation, restoration or maintenance of hedgerows (Hinsley and Bellamy, 2000; Maudsley et al., 2000; Staley et al., 2012), in-hedge trees (Redhead et al., 2013), field margins (Vickery et al., 2009; Pywell et al., 2011) and other semi-natural habitat features. This can both increase local populations of invertebrates (Vickery et al., 2009; Woodcock et al., 2010) and make them more accessible to foraging birds (Perkins et al., 2000; Benton et al., 2003), as well as providing suitable nesting habitat.

Many studies have demonstrated local and farm-scale successes of AES (Hinsley et al., 2010; Baker et al., 2012; Aebischer et al., 2016) and, recently, Bright et al. (2015) demonstrated that higher level schemes enhanced breeding densities of some priority farmland bird species even in the absence of ongoing advisory support. However, in spite of over 20 years of AES provision, and accompanying research, declines in farmland birds have continued, both in terms of individual species (Eaton et al., 2015; Harris et al., 2016) and aggregate farmland bird indicators (DEFRA, 2015). The extent to which AES have mitigated these declines remains largely unknown (Kleijn and Sutherland, 2003; Kleijn et al., 2006; Kleijn et al., 2011). Because farmland birds are mobile, with many species being partially or wholly migratory, the potential for movements of birds between winter feeding sites and breeding areas even within the same study landscape has complicated the interpretation of several studies (Hinsley et al., 2010; Aebischer et al., 2016). Therefore the overall effectiveness of AES remains unclear, with the general consensus that the current level of uptake of beneficial options is insufficient to promote a reversal of national-scale population declines (Davey et al., 2010a; Davey et al., 2010b; Baker et al., 2012). If new AES aim to be better equipped to achieve population increases, it is important to improve the understanding of how AES management affects farmland birds at the local scale, both in the immediate vicinity of AES interventions and the wider context of the farm or 
holding. It is also important to understand whether the response to AES is consistent between winter and breeding seasons, accounting for the year-round mobility of birds over farmland landscapes (Siriwardena et al., 2006; Siriwardena, 2010).

The present study seeks to understand the impact of the provision of winter food and summer breeding habitat on the local populations of a range of farmland bird species, over a long-term experiment (5 years) within a single, large-scale farmland landscape. We monitored bird numbers in both winter and the spring/summer breeding season, and utilised two levels of AES (low level uptake of simple and widely applicable AES options, more extensive uptake of more complex AES options tailored to local circumstances), a control, and a spatially separated control to allow investigation of 'spill-over' of birds from AES to non-AES treatments. The aims were to:

1. Determine the impact of AES management on winter bird numbers.

2. Investigate whether increased winter bird abundance due to AES seed provision resulted in increased numbers of breeding birds or territories.

3. Examine whether such increases were detectable at the treatment scale and/or farm scale.

\section{Methods}

\subsection{STUDY SITE}

The study took place on the Hillesden Estate, which comprises approximately 1000 ha of predominantly arable farmland close to Buckingham, central England $\left(51^{\circ} 57^{\prime} \mathrm{N}, 1^{\circ} 00^{\prime} \mathrm{W}\right.$, Figure 1$)$. The estate lies on seasonally wet clay soils with crop rotations dominated by winter wheat Triticum aestivum, winter oilseed rape Brassica napus, field beans Vicia faba and spring barley Hordeum vulgare.

The experimental layout of the Hillesden Estate was initially established in 2005/2006 in order to monitor the effects of Environmental Stewardship (ES, the then recently introduced UK AES) on farmland biodiversity, including farmland birds, and productivity (e.g. Hinsley et al., 2010; Woodcock 

experimental design was altered to improve the ability to compare the effects of management under i) Entry Level (ELS) and ii) Higher Level Stewardship (HLS) schemes, which involved the relocation of treatments and AES options to the current experimental design (Figure 1). A high level of spill-over effects between adjacent treatments (i.e. effects resulting from movement or dispersal of organisms between different treatments) had been detected after the first five years of the study (Hinsley et al., 2010; Broughton et al., 2014) so the 2011 revision of the experimental design increased the spacing between treatments and controls (Figure 1, and see Hinsley et al. 2010, Figure 1). In addition, four off-site control areas, located $2-7 \mathrm{~km}$ from the estate, were added to further investigate the extent of spill-over between treatments and controls on the estate (Figure 1). The updated experimental design of the estate and off-site controls was then monitored for birds for five years, from spring 2012 to spring 2016.

\subsection{AgRI-ENVIRONMENT TREATMENTS AND CONTROLS}

Under the two AES treatments (ELS and HLS), a percentage of land was removed from production and replaced with habitat creation options under ES (see Table 1 for details). In accordance with common agricultural practice, options were placed to minimise impact on farm productivity, mostly being situated in field corners which were difficult for farm machinery to access or along field margins. For further detail on the composition and creation of habitats at Hillesden under ES see Hinsley et al. (2010); Redhead et al. (2013); Broughton et al. (2014) and the ES handbooks (Natural England, 2012a, b). The control treatment, termed Cross Compliance (CC), represented the minimum level of environmental management required of farms receiving the Common Agricultural Policy single farm payment and was thus typical of lowland arable landscapes in central England. Under CC, fields had uncultivated, annually cut margins measuring $2 \mathrm{~m}$ in width from the centre of a bordering hedgerow, or $1 \mathrm{~m}$ from the top of a ditch. Such margins were also located on the agri-environmental treatments (ELS and HLS) wherever fields were not bordered by specific agri-environmental options. 
Off-site controls were chosen to have the same level of management as Cross Compliance controls, with similar soil types, landscape composition and cropping regimes as at Hillesden. In practice, on some off-site controls farmers did add a small number of game cover strips (mostly maize) and gamebird feeders, neither of these being present on the Hillesden estate, but these formed much lower proportions (0.3-0.5 \%) of the farmed landscape than ELS options at Hillesden.

\subsection{WINTER BIRD SURVEYS}

Winter bird numbers were surveyed on transects following a stretch of hedgerow internal to each treatment, approximately $1 \mathrm{~km}$ in length (range $659 \mathrm{~m}-1450 \mathrm{~m}$, Figure 1 ). The landscape around Hillesden is typified by hedgerows with large, mature, emergent trees (mostly English oak, Quercus robur) so hedgerows were chosen to be relatively uniform in this regard, with no lengthy sections of continuous tree canopy ('treelines'). Transects were walked monthly in December, January and February in the winters of 2012-2013, 2013-2014 and 2015-2016, with each surveyor visiting three transects per site visit, and each visit completed by 13:00 GMT. On each visit, all birds seen or heard in the hedge and in any adjacent bird food patches or field margins were recorded at their observed location on a 1:10000 scale Ordnance Survey map (zoomed to 1:2000 scale), using standard methods to denote species and activity (Bibby et al., 1992; BTO, 2016). All surveyors were professional ornithologists or ecologists with high levels of experience in ornithological field survey. The selection of transects assigned to each surveyor and the order in which they were visited was varied every month to avoid surveyor bias of likelihood of detection and effects of the time of day on the activity levels of the birds. Transects were not visited when heavy rain or strong winds were present (i.e. favourable conditions for a transect visit were approximately wind force of Beaufort 0-4 and precipitation absent or light and intermittent).

\subsection{BREEDING BIRD SURVEYS} winter surveys. Transects were walked monthly in April to July from 2012 to 2016, using identical 
methods to winter surveys, except that breeding season visits began shortly after sunrise and were completed within 4 hours. Particular attention was paid to recording activities that assisted with defining territories (e.g. song, aggression, nest building or provisioning etc.).

\subsection{PROCESSING BIRD SURVEY DATA}

All mapped records, for both winter and breeding season visits, were digitised using GIS software (ArcMAP v10.1-10.3 @ ESRI, Redlands, CA). Annotated field survey maps were scanned, and the digital copy georeferenced using a digital version of the 1:10000 Ordnance Survey data. Bird observations were then digitized by placing digital points at locations indicated by the annotated map. Because potential minor errors in the spatial placement of bird records derive from the accuracy of field annotations, georeferencing the scanned maps and the placement of digital points, exact accuracy is hard to quantify, but with experienced field surveyors and GIS staff it is likely to be less than $\pm 10 \mathrm{~m}$. This is highly likely to be sufficient to accurately determine numbers of birds and territories per transect, which were the response variables for this study. We filtered the digitized data to remove birds located more than $10 \mathrm{~m}$ from the transect hedgerows and adjacent AES habitats. This filtered out bird records associated with habitats (e.g. small woodlands, copses, small ponds) other than those the transects were intended to survey and birds seen only within crop fields, which were poorly detected by our survey method of walking along hedgerows, especially when crops were well grown (Atkinson et al., 2006). We also removed birds seen only in flight.

For breeding season data, we used GIS to overlay bird registrations across visits within each year, and then assigned birds to territories based on location and recorded bird behaviour (Bibby et al., 1992). Total winter abundance, breeding season abundance and numbers of territories (for territories where at least $50 \%$ of the territory was deemed to overlay the transect hedgerow) for each species were then calculated.

Aggregate total abundance and number of territories were also calculated for all species combined, granivorous species (i.e. those most likely to benefit from provision of winter seed, see Table 2), 
granivores excluding chaffinch (which accounted for around $40 \%$ of total granivore records), resident insectivorous species (i.e. those most likely to respond to changes in local invertebrates populations, see Table 2) and species on the UK farmland bird indicator (FBI, Gibbons et al. (1996); Gregory et al. (2005); DEFRA (2015), see Table 2). Species for which there were less than 10 records over the five years were excluded from all analyses (these were mostly migrants on passage or species from other habitats) and species without at least one territory or recorded adult for each treatment within each year were excluded from individual analyses, although they still contributed to aggregate totals (see Table 2). Species excluded by the latter threshold were either those with insufficient data for robust analysis (e.g. lesser whitethroat, bullfinch) or those where we had less confidence in the suitability of our hedgerow transect method for accurate estimation of local abundance, i.e. species associated with habitats other than hedgerows (e.g. open fields for grey partridge, woodland for woodpeckers).

For similar reasons, woodpigeons and carrion crows were omitted from analyses, despite being relatively abundant on transects. Woodpigeons were observed in large flocks within fields and/or woodland patches off the hedgerow transects, and crows were recorded in small, highly mobile groups observed to cover large distances. We therefore concluded that our hedgerow transects were not suitable for recording highly mobile, wide-ranging and gregarious species and that transect counts for such species were unlikely to provide accurate estimates of local abundance.

We here present territory results only for species groupings (i.e. all species, insectivores, granivores, granivores excluding chaffinches and farmland bird index species), with full species results available in Supplementary Material (Tables S1 and S2). This is because territory data showed very similar results to abundance for most individual species and because our method of assigning territories from the four breeding-season visits may be less informative than total abundance for species with semi-colonial breeding behaviour (e.g. linnets (Drachmann et al., 2000)), species which largely forage outside the core breeding territory (e.g. goldfinches (Conder, 1948)) or species with complex mating systems (e.g. dunnock (Birkhead, 1981; Bishton, 2001)) 
Whilst most habitat variables were broadly similar across treatments, being within the same

farmland landscape, some transects were closer to habitats which were not directly manipulated by experimental treatments but which may influence bird presence and numbers (Fuller et al., 2004).

These included improved grassland (present in small proportions of the landscape along the edge of some transects) and areas of woody vegetation (small copses and woodlands), as well as woody vegetation on the transect itself arising from in-hedge trees. We therefore quantified improved grassland area (using mapped farm management data) and extent of woody vegetation (i.e. hedges and trees, using airborne LiDAR data) as potential covariates (Table 3). LiDAR data were gathered on 28th August 2007, under conditions of full leaf canopy, from a mean flight altitude of $1190 \mathrm{~m}$ (Optech 3033 Airborne Laser Terrain Mapper, scan half angle of $20^{\circ}$, ground sampling rate of 1 pulse per square metre, each pulse supplying a first and last return elevation measurement). The use of LiDAR data for determining woody vegetation cover within the study landscape is described in Redhead et al. (2013). Although the LiDAR data were collected in 2007, the structure of woody vegetation in the study landscape has remained relatively constant over the past decade, with any changes consisting of annual growth and minor changes in hedgerow dimensions due to cutting regimes, rather than significant changes in the location or extent of woody vegetation within treatment areas.

Other habitat variables changed between years due to crop rotation, so that cropping patterns were not always consistently balanced between treatments. We therefore calculated Shannon diversity indices of crops and the coverage of cereals (the dominant crop in the landscape) per transect per year from mapped farm management data, as further potential covariates (Table 3). expected from the different agri-environmental treatments and so do not account for habitats created as part of such (e.g. grass margins). Habitat covariates were originally extracted, using GIS, 
within three buffers around the transects to explore potential effects of varying spatial scale $(10 \mathrm{~m}$, $50 \mathrm{~m}$ and $100 \mathrm{~m}$ ) but preliminary analyses showed the results from different distances to be strongly collinear, so the $100 \mathrm{~m}$ buffer was selected as containing most information on the landscape beyond the relatively consistent structure of the transect hedgerows.

\subsection{StATISTICAL ANALYSIS}

Generalized linear models were constructed to determine differences between treatments and years, and to analyse potential impact of habitat covariates. A negative binomial distribution was assumed for abundance and territory counts, with transect length as an offset term to account for variation in the length of transects (longer transects being expected to have more birds/territories). Modelling was performed using the $n b . g l m$ function of R (v3.2.2, R Core Team, 2015). For each species/grouping, we constructed all possible independent models of the form:

$$
Y \sim \text { offset }+ \text { Treatment }+ \text { Year }+(\text { Treatment* Year })+(\text { habitat variable })
$$

Where $\mathrm{Y}=$ bird abundance or territory count, offset = length of transect, and terms in parentheses are optional. Candidate models were constrained to include treatment, year and the offset term, giving a total of 16 candidate models per species analysed. We did not fit any models containing more than one habitat variable in order to avoid overfitting or attempting to include collinear variables in the same model.

We used the MuMIn package (Barton, 2015) in R to generate candidate models. Candidate models were ranked according to the corrected Akaike information criterion (AICc, (Burnham and Anderson, 2003) and the 'best' model (i.e. with lowest AICc) examined in detail. Because the 'best' model as determined by AICc may still be non-significant, overall significance of the 'best' model was determined via a likelihood ratio test against a null model consisting of only the intercept and offset terms. Where a significant effect of treatment was observed, Tukey post-hoc tests, implemented in 
the multcomp package (Hothorn et al., 2008), were applied to determine which treatments showed significant differences from one another.

\section{Results}

\subsection{WINTER BIRD SURVEYS}

All species, except song thrush, and all species groupings (Fig. 2) showed a significant effect of treatment on the abundance of birds recorded in winter (Table 4). For the majority of species, there were significantly higher numbers of birds on the Hillesden estate (i.e. Cross Compliance controls, ELS and/or HLS treatments) than on off-site controls in the winter (Tukey post hoc tests, Table 5). In some cases (granivores excluding chaffinch, farmland bird index species, dunnock, reed bunting and yellowhammer) there was no significant difference between off-site and Cross Compliance controls, but significantly higher numbers on ELS and/or HLS treatments than on Cross Compliance. Linnets showed significantly higher numbers on ELS and HLS than Cross Compliance controls but, uniquely, also showed significantly higher numbers on off-site controls than Cross Compliance controls.

Only a few individual species and species groups showed significant differences between the two AES treatments, with greater numbers on HLS than ELS treatments for only reed bunting, dunnock, insectivores and all species combined.

\subsection{BREEDING BIRD SURVEYS}

The majority of species and species groupings (Fig. 2) showed a significant effect of treatment on abundance during the breeding season, with the two exceptions being wren and yellowhammer (Table 6). However, in contrast to winter abundance, this effect was largely attributable to differences between off-site controls and the three treatments on the Hillesden estate (Tukey posthoc tests, Table 5). Only reed bunting showed significantly greater breeding season abundance on ELS or HLS treatments in comparison to Cross Compliance controls, whilst goldfinch and blue tit showed the opposite trend, with numbers in Cross Compliance controls being significantly greater 
than in ELS and HLS, respectively. Some species (blackbird, goldfinch, reed bunting) did show significantly higher numbers on HLS than ELS.

All five species groupings (all species, granivores, granivores excluding chaffinch, resident insectivores, and farmland bird index species) showed a significant effect of treatment and year on territory numbers (Fig. 2, see Supplementary Material, Table S1 for full results). As for winter and spring abundance, there were significant differences between off-site controls and treatments on the Hillesden estate. However, unlike the abundance results, numbers of territories also showed significantly greater numbers on HLS than ELS for all species groupings except insectivores. For the latter, the significant effect of treatment appeared to be due to a significant difference between the two most contrasting treatments, off-site controls and HLS (see Supplementary Material, Table S2). Territory level results for individual species can be found in supplementary material (Tables S1 and S2).

\subsection{INTERANNUAL VARIATION}

The majority of species showed significant inter-annual variation in winter abundance (Table 4).

Tukey post hoc tests showed that all significant differences in winter abundance across years were attributable to higher numbers in winter 2013-2014 and/or 2015-2016 than in 2012-2013 (Supplementary material, Table S3). For many species, numbers in the breeding season appeared less variable, with no significant year effect on breeding season abundance (Table 6). Where a significant effect of year on breeding season abundance did occur, pairwise differences between years varied across species. Robin and wren (and therefore the resident insectivores grouping) showed lower numbers in 2012 and 2013 compared to other years of the study, whilst chaffinch showed significantly lower numbers in 2016 than other years and dunnock was lower in 2013. Generally, species showing no significant year effect in winter (blackbird, goldfinch, great tit, reed bunting, song thrush) did not show a year effect in the breeding season either. Although the treatment* year interaction term was not retained in any of the 'best' models, it can be clearly seen 

some extent with year.

Nearly $70 \%$ of 'best' models contained a habitat covariate (Tables 4 and 6 ). $\triangle \mathrm{AICC}$ and Akaike weights were frequently relatively low for the 'best' models. This was mostly because the top few candidate models per species/grouping often involved habitat covariates which were to some extent correlated (e.g. total area of trees vs. total area of woody cover) and therefore showed only minor differences in model fit. This can be seen from the much higher Akaike weights achieved by summing the top ranked three models (Tables 4 and 6). The habitat covariates which appeared most frequently in best-fitted models across species and groupings were a positive effect of crop diversity ( 3 cases) or a negative effect of proportional cover of cereals (i.e. proportion of the transect surroundings covered in cereal crop).

\section{Discussion}

\subsection{IMPACT OF AES MANAGEMENT ON WINTER BIRD NUMBERS}

Provision of winter food resources on the Hillesden estate via ELS and HLS treatments co-occurred

with increased winter abundance for a wide variety of species, including nationally-declining farmland granivores (e.g. reed bunting, yellowhammer) and other generalist species of hedgerows, woodlands and gardens (e.g. blackbird, dunnock, wren, robin). This result is unsurprising, as the provision of sown bird food is well known to attract foraging birds (Perkins et al., 2008; Hinsley et al., 2010; Field et al., 2011; Aebischer et al., 2016). Even for species which are primarily insectivorous, agri-environmental field margins are likely to provide increased winter resources in comparison to crops due to an increased range of host plants and a lack of direct application of insecticides (Wilson et al., 1999; Vickery et al., 2009). The exact mechanism behind increased winter abundance of insectivores in our results is unclear, as many species which are primarily insectivores are to some 
extent omnivorous in winter (e.g. robin, dunnock) and so likely to benefit from both increased seed provision via sown bird food and any coincident increase in invertebrates in AES habitats.

337 It was apparent that the increases in bird numbers were not necessarily in direct proportion to the quantity of food provision - for many species there was no apparent difference between ELS and HLS treatments, despite the area of sown winter bird food being approximately three times greater in HLS. Birds do not necessarily occur in higher abundances at the most concentrated resources (Siriwardena et al., 2006), especially over the relatively short separation distances between ELS and HLS treatments at Hillesden (mean distance from ELS sown bird food patch to closest HLS patch = $574 \mathrm{~m})$. Previous studies have also established that that many farmland bird species readily move between patches where resources are less than $1 \mathrm{~km}$ apart (Siriwardena et al., 2006; Siriwardena, 2010), so many species will effectively treat nearby ELS and HLS treatments as part of the same foraging landscape.

For the more generalist species (e.g. blackbird, blue tit, chaffinch, robin) which showed differences only between off-site controls and transects on the Hillesden estate, detecting the exact mechanism is difficult without intensive studies using tracking or marking of individual birds (e.g. Siriwardena et al., 2006; Siriwardena, 2010). However, the results suggest that the movement of birds within the local landscape of the Hillesden estate, driven by spatial and temporal variation in food availability and weather conditions (Siriwardena et al., 2008), created a spill-over effect, such that the influence of AES treatments on winter abundance is more widely distributed than their immediate surroundings.

The unusual result for linnet, with greater winter abundance on off-site controls, ELS and HLS than on Cross Compliance controls may result from the behaviour of this species in forming particularly large, mobile winter feeding flocks. A single flock locating a viable resource, for example a game cover strip, in the otherwise resource poor local landscape of an off-site control may have a large effect on total abundance. 
361

Of potentially greater interest is the effect of winter food provision and associated habitat improvements on breeding populations, since this is far more likely to signal the status of local populations. Our results suggest that AES management under ELS and HLS may have significant, positive impacts on local breeding populations. However, in nearly all cases these impacts were only detectable when comparing off-site controls to controls and AES treatments on the Hillesden estate, suggesting that benefits were largely at a farm scale. This is likely to be due to similar spill-over effects as for winter abundance, but there are several reasons why these might be expected to be more pronounced in the breeding season. Firstly, birds may prioritise different resources over the course of the year, so that those areas that are best for winter feeding are not necessarily the most suitable for nesting or feeding offspring (Vickery et al., 2009). Secondly, territoriality in the breeding season may set an upper limit to the numbers of birds in a single treatment, forcing dispersal to other parts of the estate (Newton, 1992). Finally, birds utilising sown bird food patches in winter may have migrated at local, national or international scales (Wernham, 2002; Siriwardena et al., 2008) and so breed at sites far distant from where they spend the winter.

It is important to note that we do not attempt to distinguish between, on the one hand, a true spillover of surplus birds resulting from local population increases in HLS and ELS treatments and, on the other, the simple movement or dispersal of birds between treatments that results in the benefit of treatments being more widely distributed than their immediate surroundings. However, either or both mechanisms may explain the apparent lack of response in breeding populations to winter food provision when birds are monitored within a single farm or on sites without spatially separated controls (Hinsley et al., 2010; Aebischer et al., 2016), and emphasise the importance, and difficulties, of considering spatial scale when designing monitoring studies.

Although much of the potential effect of HLS over ELS is likely to be masked by the effects described above, some species did show significantly greater numbers in the breeding season on HLS 
treatments (blackbird, goldfinch and reed bunting abundance; number of territories for all species combined, granivores and farmland bird index species). This suggests that there are benefits from the more extensive uptake of more complex HLS options over the low level uptake of simple and widely applicable ELS ones, at least for some species.

The lack of significant differences in yellowhammer breeding season abundance between treatments on the Hillesden estate and the off-site controls, despite the clear differences seen in winter, warrants particular attention. As a declining granivore, yellowhammers would be expected to benefit from provision of resources under AES. Previous studies have presented somewhat contradictory findings regarding the association between numbers of wintering yellowhammers and those of breeding birds (Robinson et al., 2001; Whittingham et al., 2005). Our results suggest that this may be because any such association is highly likely to depend on the spatial scale at which the study is performed, and the extent to which the survey methodology samples the resources and likely locations of yellowhammers at different times of the year. Yellowhammers are relatively mobile over winter, travelling to locate food resources within the local landscape (Siriwardena et al., 2006; Siriwardena, 2010) and then dispersing to find suitable territories in early spring (Andrew, 1956). Yellowhammers also have comparatively large territories, which they actively defend against conspecifics (Andrew, 1956). This may help to drive dispersal from winter feeding areas to the surrounding landscape, as might the known reduction in seed availability on bird food patches in late winter (Hinsley et al., 2010). In contrast to yellowhammers, reed bunting abundance responded strongly to AES treatment, at both the farm scale (off-site controls vs. all other treatments) and treatment scale (ELS vs. HLS) in winter and the breeding season. On farmland, reed buntings nest and forage preferentially in tall, non-woody vegetation, avoiding hedges (Brickle and Peach, 2004; Surmacki, 2004), with the latter being apparent in our results (Table 6). Nesting and feeding opportunities for this species may, 
case for yellowhammers. Increased breeding season abundance on Cross Compliance controls over

411 off-site controls suggests that some spill-over does occur, with breeding populations on Cross

412 Compliance controls potentially enhanced by winter food provision in ELS and HLS bird food patches

413 in the winter.

414 It should be borne in mind that provision of increased food resources under AES may increase the

415 fitness of individuals and thus the ability to breed successfully or increase productivity, even if there

416 is no apparent effect on total abundance because of other limiting factors (Robb et al., 2008). For

417 example, whilst the area and proximity of tree canopy within nesting territories was previously

418 demonstrated to be strongly predictive of breeding productivity in both blue tits and great tits at the

419 Hillesden site (Redhead et al., 2013), only blue tits showed a positive response in abundance to the

420 area of woody vegetation around the transect.

\subsection{EFFECTS OF INTERANNUAL VARIATION AND HABITAT CONTEXT}

Interannual variation was evident for many species, and therefore important to account for in the models. Few patterns were consistent across species, beyond the generally lower abundance for most species in winter 2012-13 and lower breeding season abundance of insectivores in 2012 and 2013. Some of this may be due to the fact that in the first year (2012) of surveys, patches sown in the autumn of 2011 had yet to fully establish in terms of overwinter seed provision and reduced hedgerow cutting regimes would not have had time to have an impact on winter berry yield (Croxton and Sparks, 2002; Staley et al., 2012) or invertebrate numbers (Maudsley et al., 2000; Amy et al., 2015). However, the impact of weather on bird populations is also likely to be a major contributor to interannual variation (Robinson et al., 2007). Whilst winter temperatures were consistently mild across the study years, 2012-2013 was the coldest of the three surveyed (Supplementary material, Figure S4A). The breeding season in 2012 had very high rainfall, (Supplementary Material, Figure S4B) including the wettest April on record for southern England (Met Office, 2016) whilst 2013 had 
435 All of these may have combined to reduce numbers in2012 and 2013, especially for small-bodied insectivores (Robinson et al., 2007).

437 Landscape covariates were frequently included in the 'best' models, suggesting that even in an experimental design intended to make the level of AES intervention the major difference across the study landscape, bird numbers were still significantly affected by other landscape factors. The frequent negative effect of cereal cover in the local landscape is unsurprising. Cereals are the dominant agricultural vegetation in the study landscape, so in effect coverage of cereals is the inverse of total cover of semi-natural habitat, non-cropped areas and crops other than cereals. Although cereal stubbles can be beneficial for overwintering birds (Perkins et al., 2008; Field et al., 2011), the majority of Hillesden's cereals are autumn-sown and thus do not provide overwinter stubbles. In the breeding season, cereal crops are likely to be of least value compared to other land uses in the study area in terms of invertebrates and seed food supplies (Wilson et al., 1999; Woodcock et al., 2010), although not necessarily in comparison to other arable crops (Holland et al., 2012). Cereals, however, are less structurally diverse than other crops and so are likely to provide fewer opportunities for nesting and cover than oilseed rape or field beans. This is also reflected in the fact that crop diversity had a positive effect for some species. Because grass crops and fallows were included in this metric, this suggests that mixed landscapes, as well as more diverse crop rotations, can be beneficial (Holland et al., 2012; Santana et al., 2017). With current shifts in UK policy potentially moving away from EU crop diversification greening rules, simpler rotations and a greater predominance of cereals are likely outcomes, with potentially detrimental results for farmland birds.

\section{Conclusions}

Our results show that AES management, including provision of winter food resources, coincided with significantly increased winter numbers of farmland birds, especially linnets, yellowhammers and reed buntings. More importantly, they suggest that for several species this resulted in increased 
numbers of breeding birds and territories, both for farmland specialists of conservation concern (e.g. reed bunting, linnet) and more widespread and generalist species (e.g. blackbird, chaffinch, robin). Our results therefore suggest that provision of winter and breeding-season resources under agrienvironmental schemes can be of real benefit to a wide range of farmland bird species. This effect was, however, often only demonstrable when AES treatments were compared with off-site controls rather than with controls on the same farmland estate, likely due to spill-over of birds between treatments. This reinforces the importance of considering effects beyond the single-farm scale when designing schemes or studies for monitoring the effectiveness of AES, and the importance of selecting appropriately located controls (Kleijn and Sutherland, 2003). The mobility of farmland birds means that effects are not always predictable or confined to the areas of highest resource provision (Siriwardena et al., 2006; Siriwardena, 2010), suggesting that planned management of farmland landscapes at a wider scale than single farms is likely to bring increased benefits. There was some evidence for an increased benefit from the "low uptake, high intensity" HLS options over the "high uptake, low intensity" ELS ones. However, it should also be noted that whilst the levels of AES uptake and the combinations of options selected for this study were realistic, efforts were made to ensure that options were well managed and successful in achieving their desired outcomes (e.g. sown winter bird food producing good coverage of seed bearing plants). Such a situation is by no means guaranteed across the wider farmed landscape.

479 We are extremely grateful to Robin Faccenda, Richard Franklin and Jamie Orpwood for hosting the experiment, management of the experimental treatments and for access to the Hillesden estate. We are also grateful to local farmers for access to the control sites. Marek Nowakowski of the Wildlife Farming Company provided advice on establishment and management of AES options at Hillesden. Thanks also to Marta Maziarz and Mark Jitlal for help conducting field surveys and to Lucy Ridding and Ben McCrindle for assistance with digitizing survey maps. We also appreciate the contribution of 
two anonymous reviewers who provided constructive comments on an earlier version of this paper.

This work was funded by the Department for Environment, Food \& Rural Affairs (Defra). LiDAR data were obtained by the NERC Airborne Research and Survey Facility and funded by Syngenta.

\section{References}

Aebischer, N.J., Bailey, C.M., Gibbons, D.W., Morris, A.J., Peach, W.J., Stoate, C., 2016. Twenty years of local farmland bird conservation: the effects of management on avian abundance at two UK demonstration sites. Bird Study 63, 10-30.

Amy, S.R., Heard, M.S., Hartley, S.E., George, C.T., Pywell, R.F., Staley, J.T., 2015. Hedgerow rejuvenation management affects invertebrate communities through changes to habitat structure. Basic and Applied Ecology 16, 443-451.

E. Calandra. Ibis 98, 502-505. winter. Bird Study 53, 303-309.

Baker, D.J., Freeman, S.N., Grice, P.V., Siriwardena, G.M., 2012. Landscape-scale responses of birds to agri-environment management: a test of the English Environmental Stewardship scheme. Journal of Applied Ecology 49, 871-882.

Barton, K., 2015. MuMIn: Multi-Model Inference. R package version 1.15.1.

Benton, T.G., Vickery, J.A., Wilson, J.D., 2003. Farmland biodiversity: is habitat heterogeneity the key? Trends in Ecology \& Evolution 18, 182-188. Bibby, C., Burgess, N., Hill, D., 1992. Bird census techniques. British Trust for Ornithology and the Royal Society for the Protection of Birds. Academic Press, London. Birkhead, M.E., 1981. The Social Behaviour Of The Dunnock Prunella Modularis. Ibis $123,75-84$. Bishton, G., 2001. Social structure, habitat use and breeding biology of hedgerow Dunnocks Prunella modularis. Bird Study 48, 188-193. 
Brickle, N.W., Peach, W.J., 2004. The breeding ecology of Reed Buntings Emberiza schoeniclus in farmland and wetland habitats in lowland England. Ibis 146, 69-77.

Higher-tier agri-environment scheme enhances breeding densities of some priority farmland birds in England. Agriculture, Ecosystems \& Environment 203, 69-79. BTO, 2016. BTO Species Codes. informatio-theoric approch. Sringer.

Campbell, L.H., Avery, M.I., Donald, P., Evans, A.D., Green, R.E., Wilson, J.D., 1997. A review of the indirect effects of pesticides on birds. JNCC Report 227. Joint Nature Conservation Committee, Peterborough, UK. Conder, P., 1948. The Breeding Biology And Behaviour Of The Continental Goldfinch Carduelis Carduelis. Ibis 90, 493-525. on hawthorn (Crataegus monogyna) berry yields. Agriculture, ecosystems \& environment 93, 437439.

Davey, C., Vickery, J., Boatman, N., Chamberlain, D., Parry, H., Siriwardena, G., 2010a. Regional variation in the efficacy of Entry Level Stewardship in England. Agriculture, Ecosystems \& Environment 139, 121-128. Assessing the impact of Entry Level Stewardship on lowland farmland birds in England. Ibis 152, 459474. 

29.

Donald, P.F., Sanderson, F.J., Burfield, I.J., van Bommel, F.P.J., 2006. Further evidence of continentEcosystems \& Environment 116, 189-196.

Drachmann, J., Komdeur, J., Boomsma, J.J., 2000. Mate guarding in the Linnet Carduelis cannabina.

Eaton, M., Aebischer, N., Brown, A., Hearn, R., Lock, L., Musgrove, A., Noble, D., Stroud, D., Gregory, R., 2015. Birds of Conservation Concern 4: the population status of birds in the UK, Channel Islands and Isle of Man. British Birds 108, 708-746. EBCC, 2016. European wild bird indicators, 2016 update. In: (PECBMS), P.-E.C.B.M.S. (Ed.). Field, R.H., Morris, A.J., Grice, P.V., Cooke, A., 2011. The provision of winter bird food by the English Environmental Stewardship scheme. Ibis 153, 14-26. Fuller, R.J., 2000. Relationships between recent changes in lowland British agriculture and farmland bird populations: an overview. Ecology and conservation of lowland farmland birds, 5-16. Fuller, R.J., Hinsley, S.A., Swetnam, R.D., 2004. The relevance of non-farmland habitats, uncropped areas and habitat diversity to the conservation of farmland birds. Ibis 146, 22-31. species of conservation concern in the United Kingdom, Channel Islands and Isle of Man: revising the Red Data List. RSPB Conservation Review 10, 18.

557 Gregory, R.D., Van Strien, A., Vorisek, P., Meyling, A.W.G., Noble, D.G., Foppen, R.P.B., Gibbons, 558 D.W., 2005. Developing indicators for European birds. Philosophical Transactions of the Royal 
Harris, S.J., Massimino, D., Newson, S.E., Eaton, M.A., Marchant, J.H., Balmer, D.E., Noble, D.G., Gillings, S., Procter, D., Pearce-Higgins, J.W., 2016. The Breeding Bird Survey 2015. British Trust for Ornithology, Thetford.

Hinsley, S.A., Bellamy, P.E., 2000. The influence of hedge structure, management and landscape context on the value of hedgerows to birds: a review. Journal of environmental management 60, 3349.

Hinsley, S.A., Redhead, J.W., Bellamy, P.E., Broughton, R.K., Hill, R.A., Heard, M.S., Pywell, R.F., 2010. Testing agri-environment delivery for farmland birds at the farm scale: the Hillesden experiment. Ibis $152,500-514$.

Holland, J.M., Smith, B.M., Birkett, T.C., Southway, S., 2012. Farmland bird invertebrate food provision in arable crops. Annals of Applied Biology 160, 66-75.

Hothorn, T., Bretz, F., Westfall, P., 2008. Simultaneous Inference in General Parametric Models. Biometrical Journal 50, 346-363.

Kleijn, D., Baquero, R.A., Clough, Y., Díaz, M., De Esteban, J., Fernández, F., Gabriel, D., Herzog, F., Holzschuh, A., Jöhl, R., Knop, E., Kruess, A., Marshall, E.J.P., Steffan-Dewenter, I., Tscharntke, T., Verhulst, J., West, T.M., Yela, J.L., 2006. Mixed biodiversity benefits of agri-environment schemes in five European countries. Ecology Letters 9, 243-254.

Kleijn, D., Rundlöf, M., Scheper, J., Smith, H.G., Tscharntke, T., 2011. Does conservation on farmland contribute to halting the biodiversity decline? Trends in Ecology \& Evolution 26, 474-481. Kleijn, D., Sutherland, W.J., 2003. How effective are European agri-environment schemes in conserving and promoting biodiversity? Journal of Applied Ecology 40, 947-969.

Maudsley, M., West, T., Rowcliffe, H., Marshall, E., Boatman, N., Clay, D., Goodman, A., Marrs, R., Newman, J., Putwain, P., 2000. The impacts of hedge management on wildlife: preliminary results for plants and insects. Aspects of Applied Biology, 389-396. Met Office, 2016. UK Climate Summaries. 

Edition. Natural England, London.

Natural England, 2012b. Higher Level Stewardship: Environmental Stewardship Handbook, Fourth Edition. Natural England, London.

Newton, I., 1992. Experiments on the limitation of bird numbers by territorial behaviour. Biological Reviews 67, 129-173.

Newton, I., 2004. The recent declines of farmland bird populations in Britain: an appraisal of causal factors and conservation actions. Ibis $146,579-600$.

Perkins, A.J., Maggs, H.E., Wilson, J.D., 2008. Winter bird use of seed-rich habitats in agrienvironment schemes. Agriculture, Ecosystems \& Environment 126, 189-194. characteristics affecting use of lowland agricultural grassland by birds in winter. Biological Conservation 95, 279-294.

Potts, G.R., 1986. The Partridge: Pesticides, Predation and Conservation. Collins, London, U.K. Pywell, R.F., Heard, M.S., Woodcock, B.A., Hinsley, S., Ridding, L., Nowakowski, M., Bullock, J.M., 2015. Wildlife-friendly farming increases crop yield: evidence for ecological intensification. Proceedings of the Royal Society B: Biological Sciences 282.

602 Pywell, R.F., Meek, W.R., Loxton, R.G., Nowakowski, M., Carvell, C., Woodcock, B.A., 2011. Ecological restoration on farmland can drive beneficial functional responses in plant and invertebrate communities. Agriculture, Ecosystems \& Environment 140, 62-67. Statistical Computing, Vienna, Austria.

607 Redhead, J.W., Pywell, R.F., Bellamy, P.E., Broughton, R.K., Hill, R.A., Hinsley, S.A., 2013. Great tits 608 Parus major and blue tits Cyanistes caeruleus as indicators of agri-environmental habitat quality. Agriculture, Ecosystems \& Environment 178, 31-38. 
Winter feeding of birds increases productivity in the subsequent breeding season. Biology Letters 4 , 220-223.

Robinson, R.A., Baillie, S.R., Crick, H.Q.P., 2007. Weather-dependent survival: implications of climate change for passerine population processes. Ibis 149, 357-364. Robinson, R.A., Wilson, J.D., Humphrey, Q.P.C., 2001. The Importance of Arable Habitat for Farmland Birds in Grassland Landscapes. Journal of Applied Ecology 38, 1059-1069. Combined effects of landscape composition and heterogeneity on farmland avian diversity. Ecology and Evolution 7, 1212-1223. Schaub, M., Martinez, N., Tagmann-loset, A., Weisshaupt, N., Maurer, M.L., Reichlin, T.S., Abadi, F., Zbinden, N., Jenni, L., Arlettaz, R., 2010. Patches of Bare Ground as a Staple Commodity for Declining Ground-Foraging Insectivorous Farmland Birds. PLOS ONE 5, e13115. Siriwardena, G.M., 2010. The importance of spatial and temporal scale for agri-environment scheme delivery. Ibis 152, 515-529. Siriwardena, G.M., Calbrade, N.A., Vickery, J.A., 2008. Farmland birds and late winter food: does seed supply fail to meet demand? Ibis 150, 585-595. Siriwardena, G.M., Calbrade, N.A., Vickery, J.A., Sutherland, W.J., 2006. The effect of the spatial distribution of winter seed food resources on their use by farmland birds. Journal of Applied Ecology $43,628-639$. Siriwardena, G.M., Stevens, D.K., Anderson, G.Q.A., Vickery, J.A., Calbrade, N.A., Dodd, S., 2007. The effect of supplementary winter seed food on breeding populations of farmland birds: evidence from two large-scale experiments. Journal of Applied Ecology 44, 920-932. Staley, J.T., Sparks, T.H., Croxton, P.J., Baldock, K.C., Heard, M.S., Hulmes, S., Hulmes, L., Peyton, J., Amy, S.R., Pywell, R.F., 2012. Long-term effects of hedgerow management policies on resource provision for wildlife. Biological Conservation 145, 24-29. 

farmland in Western Poland. Ornis Fennica 81, 137-143. conservation: A review of food resource provision for farmland birds. Agriculture, Ecosystems \& Environment 133, 1-13.

641 Wernham, C., 2002. \{The Migration Atlas: Movements of the Birds of Britain and Ireland\}.

642 Whittingham, M.J., Swetnam, R.D., Wilson, J.D., Chamberlain, D.E., Freckleton, R.P., 2005. Habitat

643 selection by yellowhammers Emberiza citrinella on lowland farmland at two spatial scales:

644 implications for conservation management. Journal of applied ecology 42, 270-280.

645 Wilson, J.D., Evans, A.D., Grice, P.V., 2009. Bird conservation and agriculture. Cambridge University 646 Press Cambridge.

647 Wilson, J.D., Morris, A.J., Arroyo, B.E., Clark, S.C., Bradbury, R.B., 1999. A review of the abundance and diversity of invertebrate and plant foods of granivorous birds in northern Europe in relation to agricultural change. Agriculture, Ecosystems \& Environment 75, 13-30.

650 Woodcock, B.A., Redhead, J., Vanbergen, A.J., Hulmes, L., Hulmes, S., Peyton, J., Nowakowski, M., Pywell, R.F., Heard, M.S., 2010. Impact of habitat type and landscape structure on biomass, species richness and functional diversity of ground beetles. Agriculture, Ecosystems \& Environment 139, 181-186. 


\section{Option Description}

Total area of land removed from agricultural production

Permanent tussocky grass margins

Pollen- and nectarproducing flowers

Spring sown wild bird seed mixture

Autumn sown wild bird seed mixture

Perennial wildflowers

Enhanced permanent grass margins

Extended overwintered stubble

Supplementary feeding for wild birds

\section{Option Code}

per ELS treatment

per HLS

treatment

Detail
Land which would otherwise be used for arable crops, replaced with AES options

$\begin{array}{llll}2 \text { margins } & 1 \text { margin } & \text { Uncut except in first year of establishment (to } \\ \text { EE3 EJ9 } & (6 \mathrm{~m} \text { wide }) & (12 \mathrm{~m} \text { wide }) & \text { supress weeds })\end{array}$

$\begin{array}{lll}\text { EF4, HE10 } & 1 \text { patch } & \begin{array}{l}3 \text { patches } \\ 1 \text { margin }\end{array} \\ \text { EF2, HF2, } & 1 \text { patch } & 2 \text { patches } \\ \text { HF12 } & \end{array}$

Contained a variety of flowering species including legumes (e.g. Trifolium spp.) $)^{\ddagger}$

See Hinsley et al. (2010) for details of seed mixes $^{\ddagger}$

HF12

1 patch

EF1, EF4 HE10

3 patches

Autumn sown to provide seed resources earlier in the season ${ }^{\dagger}$

Contained a wide variety of 'meadow' flowers

HE10

1 margin

(12m wide)

EF22

1 area

1 site

(100m track)
Contained a mixture of grass and wildflower species

Provided late-winter seed resources. Relocated within treatments every year

$12.5 \mathrm{~kg}$ seed* $^{*}$ spread twice per week from beginning January - end April

* Seed mix comprised $68 \%$ wheat, $10 \%$ white millet, $10 \%$ red millet, $6 \%$ canary and $6 \%$ oil seed rape. Supplied by Vine House Farm Ltd., Lincolnshire

† Seed mix comprised $1 \%$ fodder radish, $5 \%$ kale, $1 \%$ stubble turnip, $38 \%$ winter linseed, $5 \%$ gold of pleasure, $25 \%$ winter barley, $25 \%$ winter triticale. Supplied by Cotswold Seeds Ltd., Gloucestershire

‡Rotational - these options exchanged location within treatments after 3 years

660 
670 Table 2 Total number of records within $10 \mathrm{~m}$ of transects and/or adjacent patches over spring and

671 winter visits, across study years, and mean ( \pm standard error) numbers per year. Only species with a

672 total of at least ten records in either winter or the breeding season are shown. Migratory (or largely

673 so) species are indicated by $S=$ summer or $W=$ winter. Species groupings are indicated by columns

674 GV (Granivorous), IV (resident insectivorous) and FBI (farmland bird indicator). Note that total winter

675 numbers appear lower due to fewer visits per year (three vs. four) and fewer censuses overall (three

676 vs five). Bold type indicates species with at least one record/territory per treatment per year.

\begin{tabular}{|c|c|c|c|c|c|c|c|c|c|c|c|}
\hline \multirow[b]{2}{*}{ Common name } & \multirow{2}{*}{ Scientific name } & \multirow{2}{*}{ Migrants } & \multirow{2}{*}{ GV } & \multirow{2}{*}{ IV } & \multirow{2}{*}{ FBI } & \multicolumn{2}{|c|}{ Winter numbers } & \multicolumn{2}{|c|}{ Breeding Season } & \multicolumn{2}{|c|}{ Territories } \\
\hline & & & & & & $\overline{\text { Total }}$ & Mean $( \pm$ SE) & Total & Mean $( \pm S E)$ & Total & Mean $( \pm$ SE) \\
\hline Blackbird & Turdus merula & & & & & 569 & $190( \pm 11)$ & 1067 & $213( \pm 10)$ & 276 & $55( \pm 3)$ \\
\hline Blackcap & Sylvia atricapilla & $S$ & & & & 0 & 0 & 43 & $9( \pm 2)$ & 6 & $3( \pm 2)$ \\
\hline Blue tit & Cyanistes caeruleus & & & & & 466 & $155( \pm 20)$ & 763 & $153( \pm 5)$ & 186 & $37( \pm 1)$ \\
\hline Bullfinch & Pyrrhula pyrrhula & & $x$ & & & 41 & $14( \pm 2)$ & 58 & $12( \pm 2)$ & 8 & $4( \pm 3)$ \\
\hline Buzzard & Buteo buteo & & & & & 12 & $6( \pm 4)$ & 6 & $1( \pm 0)$ & - & - \\
\hline Carrion crow & Corvus corone & & & & & 88 & $29( \pm 4)$ & 273 & $55( \pm 9)$ & - & - \\
\hline Chaffinch & Fringilla coelebs & & $\mathbf{x}$ & & & 1157 & $386( \pm 65)$ & 1777 & $355( \pm 31)$ & 450 & $90( \pm 7)$ \\
\hline Chiffchaff & Phylloscopus collybita & S & & & & 0 & 0 & 67 & $13( \pm 3)$ & 16 & $5( \pm 1)$ \\
\hline Dunnock & Prunella modularis & & & $\mathbf{x}$ & & 418 & $139( \pm 40)$ & 645 & $129( \pm 12)$ & 224 & $45( \pm 4)$ \\
\hline Fieldfare & Turdus pilaris & W & & & & 1015 & $338( \pm 116)$ & 0 & 0 & - & - \\
\hline Goldfinch & Carduelis carduelis & & $\mathbf{x}$ & & & 46 & $23( \pm 6)$ & 273 & $55( \pm 8)$ & 4 & $4( \pm 0)$ \\
\hline Greenfinch & Chloris chloris & & $x$ & & $\mathrm{x}$ & 51 & $17( \pm 5)$ & 56 & $11( \pm 2)$ & 5 & $3( \pm 2)$ \\
\hline Grey partridge & Perdix perdix & & & & $x$ & 9 & $3( \pm 1)$ & 20 & $5( \pm 3)$ & - & - \\
\hline Great tit & Parus major & & & & & 187 & $62( \pm 5)$ & 427 & $85( \pm 9)$ & 120 & $24( \pm 3)$ \\
\hline Green woodpecker & Picus viridis & & & & & 7 & $2( \pm 0)$ & 19 & $4( \pm 1)$ & - & - \\
\hline Great spotted woodpecker & Dendrocopos major & & & & & 6 & $2( \pm 1)$ & 29 & $6( \pm 1)$ & - & - \\
\hline House sparrow & Passer domesticus & & & & & 5 & $5( \pm 0)$ & 37 & $9( \pm 3)$ & - & - \\
\hline Jackdaw & Corvus monedula & & & & $x$ & 111 & $37( \pm 7)$ & 129 & $26( \pm 6)$ & - & - \\
\hline Kestrel & Falco tinnunculus & & & & $x$ & 7 & $4( \pm 1)$ & 12 & $4( \pm 1)$ & - & - \\
\hline Lesser whitethroat & Sylvia curruca & s & & & & 0 & 0 & 60 & $12( \pm 2)$ & 9 & $5( \pm 2)$ \\
\hline Linnet & Carduelis cannabina & & $\mathbf{x}$ & & $\mathbf{x}$ & 800 & $267( \pm 136)$ & 728 & $146( \pm 16)$ & 127 & $25( \pm 3)$ \\
\hline Long tailed tit & Aegithalos caudatus & & & & & 30 & $10( \pm 3)$ & 71 & $14( \pm 2)$ & - & - \\
\hline Magpie & Pica pica & & & & & 19 & $10( \pm 2)$ & 50 & $10( \pm 2)$ & - & - \\
\hline Meadow pipit & Anthus pratensis & & & & & 27 & $14( \pm 11)$ & 21 & $5( \pm 2)$ & - & - \\
\hline Pheasant & Phasianus colchicus & & & & & 66 & $22( \pm 7)$ & 59 & $12( \pm 2)$ & - & - \\
\hline Redwing & Turdus iliacus & W & & & & 559 & $186( \pm 98)$ & 0 & 0 & - & - \\
\hline Reed bunting & Emberiza schoeniclus & & $\mathbf{x}$ & & $\mathbf{x}$ & 257 & $86( \pm 36)$ & 131 & $26( \pm 5)$ & 51 & $10( \pm 1)$ \\
\hline Red legged partridge & Alectoris rufa & & & & & 39 & $13( \pm 3)$ & 16 & $3( \pm 1)$ & & \\
\hline Robin & Erithacus rubecula & & & $\mathbf{x}$ & & 267 & $89( \pm 12)$ & 356 & $71( \pm 10)$ & 126 & $25( \pm 4)$ \\
\hline Song thrush & Turdus philomelos & & & & & 223 & $74( \pm 3)$ & 141 & $28( \pm 4)$ & 54 & $11( \pm 2)$ \\
\hline Starling & Sturnus vulgaris & & & & $\mathrm{x}$ & 193 & $64( \pm 36)$ & 43 & $9( \pm 5)$ & - & - \\
\hline
\end{tabular}




\begin{tabular}{|c|c|c|c|c|c|c|c|c|c|c|c|}
\hline Stock dove & Columba oenas & & & & $x$ & 21 & $7( \pm 2)$ & 47 & $9( \pm 1)$ & - & - \\
\hline Whitethroat & Sylvia communis & $\mathbf{S}$ & & & $\mathbf{X}$ & 0 & 0 & 815 & $163( \pm 8)$ & 249 & $50( \pm 3)$ \\
\hline Woodpigeon & Columba palumbus & & & & $x$ & 493 & $164( \pm 56)$ & 232 & $46( \pm 9)$ & - & - \\
\hline Wren & Troglodytes troglodytes & & & $\mathbf{x}$ & & 222 & $74( \pm 10)$ & 533 & $107( \pm 22)$ & 191 & $38( \pm 7)$ \\
\hline Yellowhammer & Emberiza citrinella & & $\mathbf{x}$ & & $\mathbf{X}$ & 766 & $255( \pm 80)$ & 1238 & $248( \pm 10)$ & 297 & $59( \pm 2)$ \\
\hline Yellow wagtail & Motacilla flava & $S$ & & & $x$ & 0 & 0 & 40 & $8( \pm 2.9)$ & 8 & $4( \pm 2.0)$ \\
\hline
\end{tabular}

- Insufficient data/not suitable for territory assignment

677 
678 Table 3 Landscape covariates calculated within the surroundings of each transect.

\begin{tabular}{|c|c|c|c|c|c|}
\hline $\begin{array}{l}\text { Variable } \\
\text { group }\end{array}$ & $\begin{array}{l}\text { Data } \\
\text { source }\end{array}$ & $\begin{array}{l}\text { Variable } \\
\text { name }\end{array}$ & Description & $\begin{array}{l}\text { Mean } \\
( \pm S D)\end{array}$ & $\begin{array}{c}\text { Range } \\
\text { (Min - Max) }\end{array}$ \\
\hline \multirow{4}{*}{ Land use } & \multirow{4}{*}{$\begin{array}{l}\text { Mapped farm } \\
\text { management } \\
\text { records }\end{array}$} & Div. Crop & Shannon diversity of crops & $0.18( \pm 0.24)$ & $0-0.67$ \\
\hline & & Div. Habitat & $\begin{array}{l}\text { Shannon diversity of broad habitats } \\
\text { (arable crop, grass crop, woodland) }\end{array}$ & $0.38( \pm 0.22)$ & $0-0.75$ \\
\hline & & $\%$ Cereal & $\begin{array}{l}\text { Percentage cover of cereal cropped } \\
\text { fields }\end{array}$ & $48.43( \pm 38.63)$ & $0-99.85$ \\
\hline & & $\%$ Grass & $\begin{array}{l}\text { Percentage cover of grass-cropped } \\
\text { fields }\end{array}$ & $6.55( \pm 8.53)$ & $0-26.6$ \\
\hline \multirow{3}{*}{$\begin{array}{l}\text { Woody } \\
\text { cover }\end{array}$} & \multirow{3}{*}{ LiDAR data } & \% Woody & $\begin{array}{l}\text { Percentage cover of all woody } \\
\text { vegetation (hedges, trees, copses) }\end{array}$ & $7.00( \pm 1.96)$ & $4.23-11.13$ \\
\hline & & $\%$ Tree & $\begin{array}{l}\text { Percentage cover of trees over } 3 \mathrm{~m} \\
\text { high }\end{array}$ & $4.66( \pm 1.78)$ & $2.09-7.92$ \\
\hline & & $\%$ Hedge & $\begin{array}{l}\text { Percentage cover of hedgerows } \\
>1 \mathrm{~m} \text { and }<3 \mathrm{~m} \text { high }\end{array}$ & $2.34( \pm 0.58)$ & $1.07-3.61$ \\
\hline
\end{tabular}

679 
Table 4. Results of generalized linear models for winter abundance (i.e. total number of adult bird

681 observations), using multi-model comparisons to select the 'best' fitting model for each

682 species/group. Results are: $\triangle \mathrm{AICC}$ (difference in AICc from the top ranked model to the second

683 ranked model), Akaike weights (for the top model only and summed over the top three models),

684 likelihood ratio test of the top ranked model against a null model, $\mathrm{p}$ value of Moran's I test of spatial

685 autocorrelation. Covariates are named as in Table 3. The significance of factors and covariates are

686 denoted as follows: ${ }^{*} p<0.05,+p<0.05$ and positive coefficient, $-p<0.05$ and negative coefficient

\begin{tabular}{|c|c|c|c|c|c|c|c|c|c|c|}
\hline \multirow[b]{2}{*}{ Species } & \multirow[b]{2}{*}{$\frac{0}{8}$} & \multirow[b]{2}{*}{ 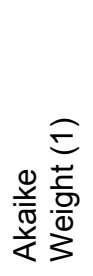 } & \multirow[b]{2}{*}{ 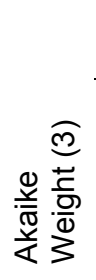 } & \multicolumn{3}{|c|}{$\begin{array}{c}\text { Likelihood ratio } \\
\text { test }\end{array}$} & \multicolumn{2}{|c|}{ Factors } & \multicolumn{2}{|c|}{ Habitat covariates } \\
\hline & & & & $\pi^{2}$ & $\begin{array}{l}\frac{0}{2} \\
\frac{2}{20} \\
0\end{array}$ & 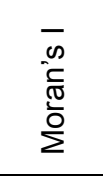 & 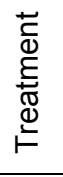 & 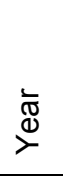 & 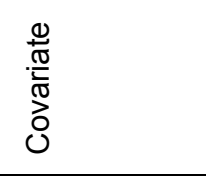 & 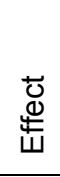 \\
\hline All species & 1.08 & 0.28 & 0.59 & 33.78 & $<0.001$ & 0.013 & * & * & Div. Habitat & + \\
\hline Granivores & 0.19 & 0.21 & 0.55 & 44.58 & $<0.001$ & 0.009 & * & * & Div. Crop & + \\
\hline $\begin{array}{l}\text { Granivores excl. } \\
\text { chaffinch }\end{array}$ & 1.02 & 0.25 & 0.53 & 40.48 & $<0.001$ & 0.780 & * & * & & \\
\hline Insectivores & 1.92 & 0.30 & 0.51 & 46.67 & $<0.001$ & 0.866 & * & * & & \\
\hline $\begin{array}{l}\text { Farmland bird } \\
\text { index }\end{array}$ & 2.61 & 0.33 & 0.51 & 33.29 & $<0.001$ & 0.717 & * & * & & \\
\hline Blackbird & 1.33 & 0.28 & 0.53 & 23.11 & $<0.001$ & 0.722 & * & & Div. Crop & + \\
\hline Blue tit & 6.01 & 0.84 & 0.91 & 39.10 & $<0.001$ & 0.082 & * & * & $\%$ Cereal & - \\
\hline Chaffinch & 1.40 & 0.54 & 0.87 & 32.45 & $<0.001$ & 0.080 & * & * & Div. Habitat & + \\
\hline Dunnock & 2.39 & 0.30 & 0.47 & 40.80 & $<0.001$ & 0.531 & * & * & & \\
\hline Goldfinch & 0.86 & 0.25 & 0.55 & 14.60 & 0.012 & 0.793 & * & & & \\
\hline Great tit & 1.56 & 0.37 & 0.67 & 15.72 & 0.015 & 0.322 & * & & $\%$ Cereal & - \\
\hline Linnet & 1.61 & 0.46 & 0.76 & 43.13 & $<0.001$ & 0.951 & * & * & $\%$ Woody & + \\
\hline Reed bunting & 4.78 & 0.81 & 0.94 & 35.35 & $<0.001$ & 0.491 & * & & $\%$ Hedge & - \\
\hline Robin & 5.60 & 0.80 & 0.89 & 33.99 & $<0.001$ & 0.380 & * & * & \% Cereal & - \\
\hline Song thrush & 1.29 & 0.25 & 0.49 & 5.71 & $0.335^{\ddagger}$ & 0.792 & & & & \\
\hline Wren & 0.77 & 0.26 & 0.60 & 16.64 & 0.005 & 0.696 & * & * & & \\
\hline Yellowhammer & 0.14 & 0.28 & 0.62 & 32.14 & $<0.001$ & 0.435 & * & * & & \\
\hline
\end{tabular}

‡ No significant difference from null model 
688

689

690

691

692

Table 5. Results of Tukey post hoc tests between treatments for adult bird winter and breeding season abundance (total number of adult birds). All pairwise comparisons between treatments are represented $(\mathrm{OSC}=$ off-site control, $\mathrm{CC}=$ Cross Compliance, $\mathrm{ELS}=$ Entry Level Stewardship, $\mathrm{HLS}=$

Higher Level Stewardship). +/- indicates the direction of a significant difference between treatments, e.g. OSC relative to $\mathrm{CC}$, etc.

\begin{tabular}{|c|c|c|c|c|c|c|c|c|c|c|c|c|}
\hline \multirow[b]{2}{*}{ Species } & \multicolumn{6}{|c|}{ Winter abundance } & \multicolumn{6}{|c|}{ Breeding season abundance } \\
\hline & $\begin{array}{l}0 \\
0 \\
0 \\
0\end{array}$ & $\begin{array}{l}0 \\
\Psi \\
\tilde{D} \\
0\end{array}$ & $\begin{array}{l}\text { D) } \\
\text { İ } \\
\text { On }\end{array}$ & $\frac{\omega}{\tilde{U}}$ & $\frac{\stackrel{\infty}{\mathcal{T}}}{0}$ & $\frac{\stackrel{\infty}{\overrightarrow{1}}}{\text { की }}$ & $\begin{array}{l}0 \\
0 \\
0 \\
0\end{array}$ & $\frac{\mathscr{W}}{\tilde{U}}$ & $\frac{0}{\text { D }}$ & $\frac{\omega}{\tilde{U}}$ & $\frac{\stackrel{n}{T}}{0}$ & $\frac{\infty}{\vec{x}}$ \\
\hline All species & - & - & - & & - & - & - & - & - & & & \\
\hline Granivores & - & - & - & & - & & - & - & - & & & \\
\hline Granivores excl. chaffinch & & - & - & - & - & & - & & - & & & \\
\hline Insectivores & - & - & - & & - & - & - & & - & & & \\
\hline Farmland bird index & & - & - & - & - & & - & - & - & & & \\
\hline Blackbird & - & - & - & & & & - & - & - & & & - \\
\hline Blue tit & - & - & - & + & + & & - & - & & & + & + \\
\hline Chaffinch & - & - & - & & & & - & - & - & & & \\
\hline Dunnock & & - & - & & - & - & & & - & & & \\
\hline Goldfinch & & & & & & & - & & - & + & & - \\
\hline Great tit & - & & & & & & - & - & - & & & \\
\hline Linnet & + & & & - & - & & - & - & - & & & \\
\hline Reed bunting & & - & - & - & - & - & - & - & - & & - & - \\
\hline Robin & - & - & - & & & & - & - & - & & & \\
\hline Song thrush & & & & & & & - & - & - & & & \\
\hline Whitethroat & & Not pr & sent & win & & & - & - & - & & & \\
\hline Wren & & & - & & - & & & & & & & \\
\hline Yellowhammer & & - & - & - & - & & & & & & & \\
\hline
\end{tabular}

693 
Table 6. Results of generalized linear models for breeding season abundance (i.e. total number of

702 adult bird observations), using multi-model comparisons to select the 'best' fitting model for each

703 species/group. Results are: $\triangle \mathrm{AICC}$ (difference in AICc from the top ranked model to the second

704 ranked model), Akaike weights (for the top model only and summed over the top three models),

705 likelihood ratio test of the top ranked model against a null model, $\mathrm{p}$ value of Moran's I test of spatial

706 autocorrelation Covariates are named as in Table 3. The significance of factors and covariates are

707 denoted as follows: ${ }^{*} p<0.05,+p<0.05$ and positive coefficient, $-p<0.05$ and negative coefficient

\begin{tabular}{|c|c|c|c|c|c|c|c|c|c|c|}
\hline \multirow[b]{2}{*}{ Species } & \multirow[b]{2}{*}{$\frac{0}{\delta}$} & \multirow[b]{2}{*}{ 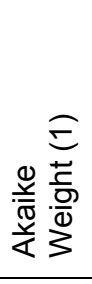 } & \multirow[b]{2}{*}{ 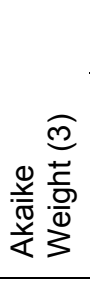 } & \multicolumn{3}{|c|}{$\begin{array}{c}\text { Likelihood ratio } \\
\text { test }\end{array}$} & \multicolumn{2}{|c|}{ Factors } & \multicolumn{2}{|c|}{ Habitat covariates } \\
\hline & & & & $\sqrt{x}$ & $\begin{array}{l}\frac{0}{2} \\
\frac{10}{2} \\
2\end{array}$ & \begin{tabular}{l}
$\bar{\infty}$ \\
\hdashline$\frac{1}{\pi}$ \\
$\frac{0}{0}$ \\
$\sum$
\end{tabular} & 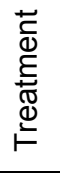 & $\stackrel{\overline{\mathbb{D}}}{\stackrel{\succ}{ঠ}}$ & $\begin{array}{l}\frac{0}{.0} \\
. \frac{\pi}{2} \\
\frac{0}{20} \\
0 \\
0\end{array}$ & 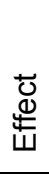 \\
\hline All species & 8.61 & 0.97 & 1.00 & 57.36 & $<0.001$ & $<0.001$ & * & * & $\%$ Cereal & - \\
\hline Granivores & 8.43 & 0.98 & 1.00 & 47.26 & $<0.001$ & $<0.001$ & * & * & $\%$ Cereal & - \\
\hline $\begin{array}{l}\text { Granivores excl. } \\
\text { chaffinch }\end{array}$ & 5.66 & 0.93 & 0.99 & 23.30 & $<0.001$ & $<0.001$ & * & & $\%$ Cereal & - \\
\hline Insectivores & 3.17 & 0.77 & 0.98 & 47.63 & $<0.001$ & $<0.001$ & * & * & $\%$ Cereal & - \\
\hline $\begin{array}{l}\text { Farmland bird } \\
\text { index }\end{array}$ & 9.53 & 0.99 & 1.00 & 38.30 & $<0.001$ & 0.781 & * & * & $\%$ Cereal & - \\
\hline Blackbird & 0.34 & 0.21 & 0.54 & 33.06 & $<0.001$ & 0.083 & * & & Div. Crop & + \\
\hline Blue tit & 0.29 & 0.20 & 0.53 & 39.63 & $<0.001$ & 0.994 & * & & $\%$ Woody & + \\
\hline Chaffinch & 0.14 & 0.22 & 0.59 & 72.51 & $<0.001$ & 0.047 & * & * & & \\
\hline Dunnock & 7.02 & 0.89 & 0.94 & 31.49 & $<0.001$ & 0.420 & * & * & $\%$ Cereal & - \\
\hline Goldfinch & 1.59 & 0.69 & 1.00 & 28.21 & $<0.001$ & 0.575 & * & & $\%$ Woody & - \\
\hline Great tit & 0.48 & 0.23 & 0.53 & 22.10 & 0.002 & 0.181 & * & * & & \\
\hline Linnet & 9.28 & 0.98 & 1.00 & 23.84 & 0.002 & 0.273 & * & & $\%$ Cereal & - \\
\hline Reed bunting & 13.54 & 1.00 & 1.00 & 44.21 & $<0.001$ & 0.726 & * & & $\%$ Hedge & - \\
\hline Robin & 1.75 & 0.41 & 0.70 & 39.25 & $<0.001$ & 0.819 & * & * & Div. Habitat & + \\
\hline Song thrush & 1.45 & 0.39 & 0.68 & 30.43 & $<0.001$ & 0.124 & * & & $\%$ Hedge & - \\
\hline Whitethroat & 6.33 & 0.93 & 0.99 & 39.95 & $<0.001$ & 0.253 & * & & $\%$ Cereal & - \\
\hline Wren & 3.91 & 0.76 & 0.91 & 60.82 & $<0.001$ & 0.589 & & * & $\%$ Cereal & - \\
\hline Yellowhammer & 0.99 & 0.24 & 0.53 & 9.19 & $0.327^{\ddagger}$ & 0.144 & & & & \\
\hline
\end{tabular}


‡ No significant difference from null model 


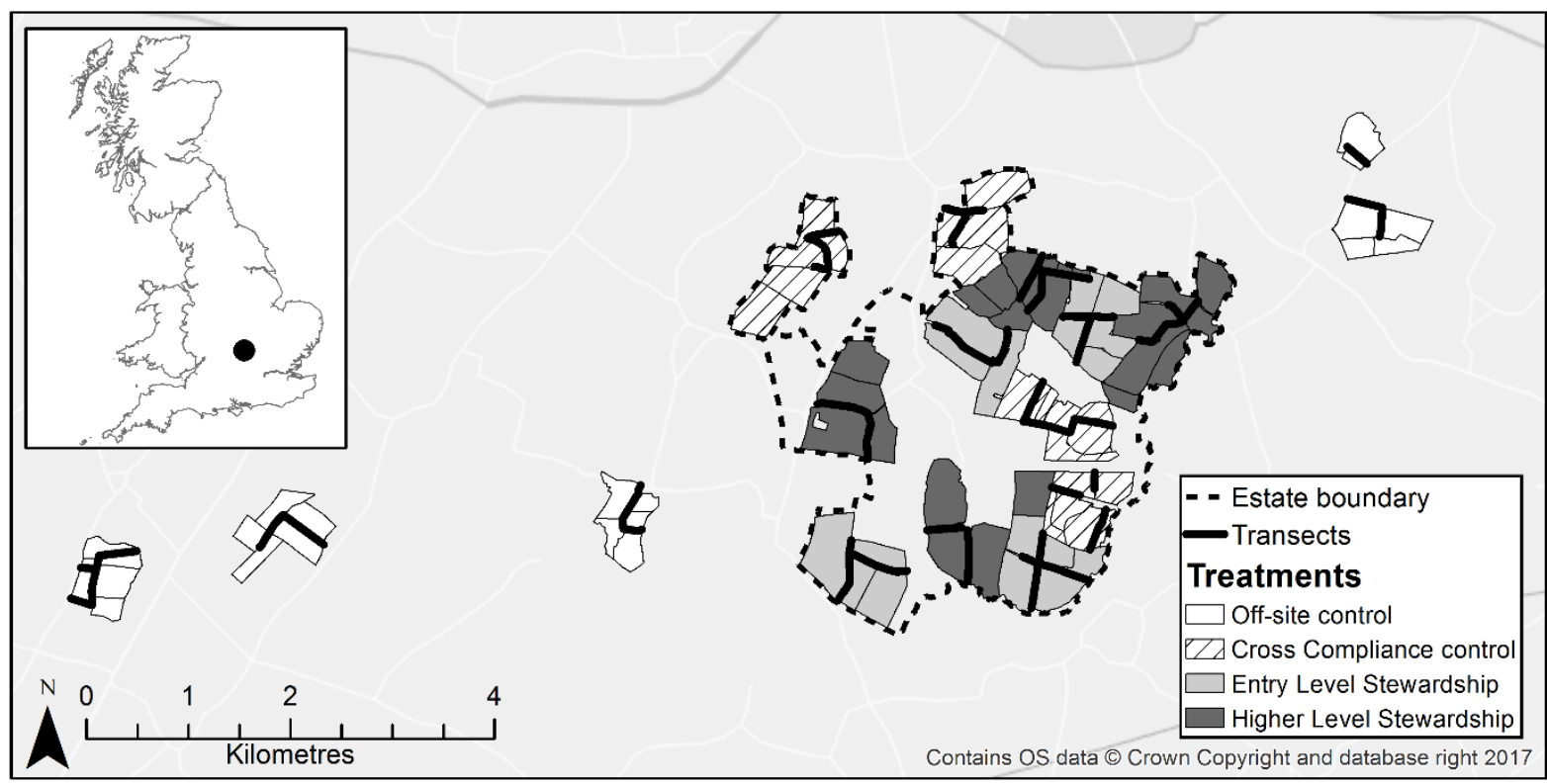

Figure 1. Map of the study area showing experimental treatments on the Hillesden Estate and the central England. 

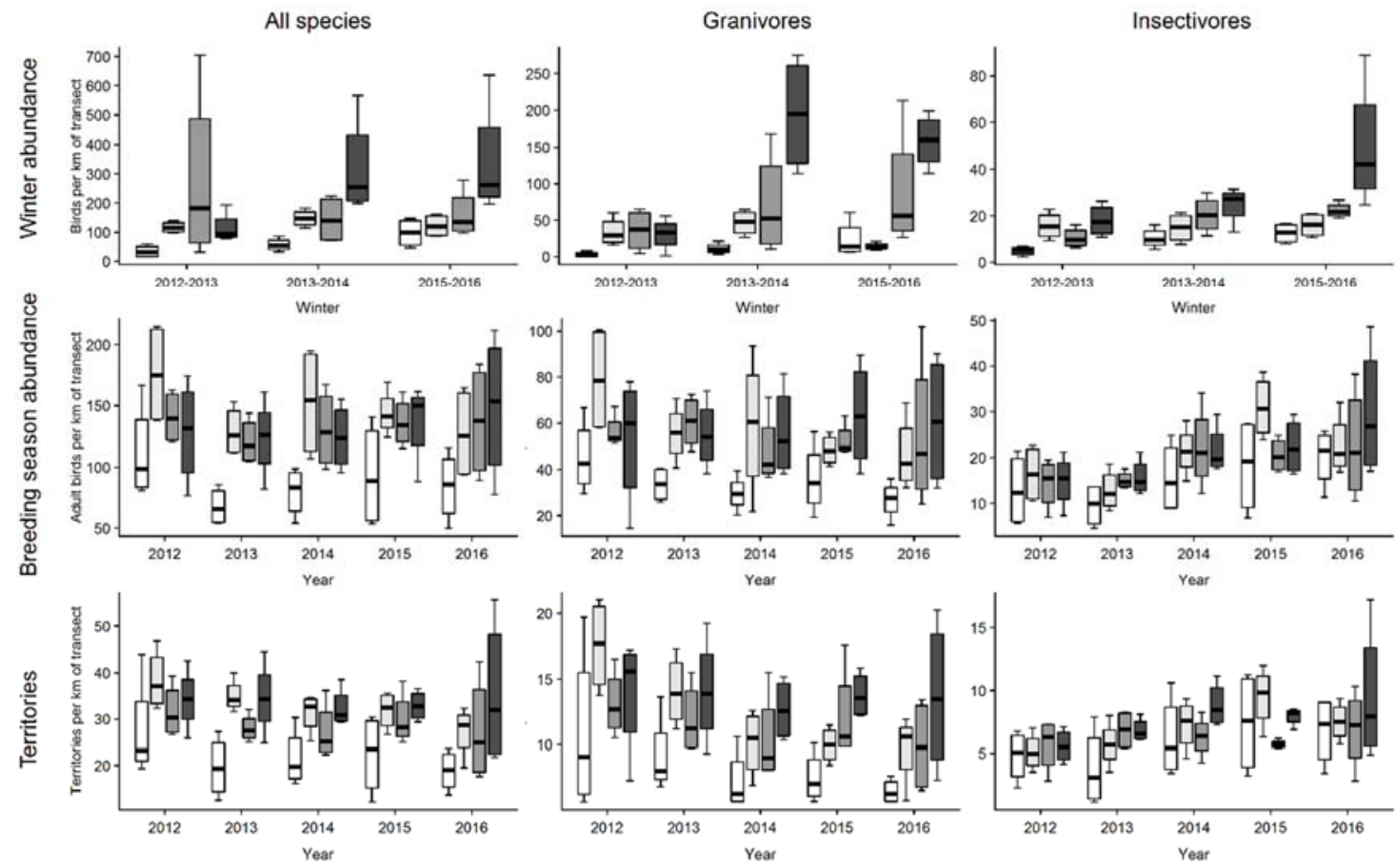

Figure 2. Boxplots of winter, breeding season and territory abundance per kilometre of transect by

treatment and year, for three groupings of farmland birds (all species, granivores and resident

insectivores). Treatment is indicated by colour fill of boxes: white $=$ off-site control, light grey $=$ Cross

721

Compliance control, mid grey = Entry Level Stewardship, dark grey = Higher Level Stewardship. 